\title{
Comparative Study between Heavy-weight Mesh and Light-weight Mesh in Ventral Hernia Repair
}

M.M.RezK, G.E.Saleh, H.G.El-Gohary and A.W.Allam

General Surgery Dept., Faculty of Medicine, Benha Univ., Benha, Egypt

E-Mail: Allam@gmail.com

\begin{abstract}
A ventral hernia occurs when the contents of a body cavity bulge out of the area where they are normally contained. These contents, usually portions of intestine or abdominal fatty tissue, are enclosed in the thin membrane that naturally lines the inside of the abdominal cavity (peritoneum). This work aims to study and compare the outcome of using heavy-weight mesh and light-weight mesh in ventral hernia repair.: In our study, The number of patients was 120 which were divided randomly in to two groups: $\square$ Group A: Representing mesh repair using heavyweight mesh ( Prolene mesh). $\square$ Group B: Representing mesh repair using lightweight mesh ( Ultrapro mesh ). The lightweight mesh offers benefits over heavyweight mesh for ventral hernia repair by reducing the incidence of chronic pain and foreign body sensation. Complications - seroma and infection - with lightweight meshes were less than heavyweight meshes, recurrence rate was high with heavyweight meshes than lightweight meshes.It could be concluded that the repair of primary ventral hernia cases can be made with light weight mesh or heavy weight mesh, but the cost-benefits of using LW mesh is still main obstacles. We suggest that light weight mesh is an option for repair of primary ventral hernia as its complications are less and the quality of life is better .
\end{abstract}

Keywords: Ventral hernia, Lightweight mesh, Heavyweight mesh.

\section{Introduction}

A ventral hernia occurs when the contents of a body cavity bulge out of the area where they are normally contained. These contents, usually portions of intestine or abdominal fatty tissue, are enclosed in the thin membrane that naturally lines the inside of the abdominal cavity (peritoneum) [1].

Ventral hernia may be spontaneous (primary ventral hernia) or at the site of a previous surgical incision (incisional hernia). Ventral hernias include only hernias of the anterior abdominal wall [2].

A primary ventral hernia is classified as a (para-) umbilical (regarding to the navel), epigastric (upper central region of the abdomen) or Spigelian hernia (between the muscles of the abdominal wall). The incisional and paraumbilical hernias constitute about $85 \%$ of the overall ventral abdominal hernias [3].

The definitive treatment of all hernias, regardless of their origin or type, is surgical repair. The risks of delayed surgery are primarily related to the risks of incarceration and strangulation, which necessitates emergency surgery [4].

Depending on the weight per surface area expressed as $\mathrm{g} / \mathrm{m} 2$, reticular prostheses may be classified into the classic heavy-weights (HWs) and light-weights (LWs) according to whether their density is above or below a cut-off of 80 $90 \mathrm{~g} / \mathrm{m} 2$ [5].

When hernias are surgically repaired, the mesh can be placed using the onlay, sublay or inlay technique [6].

Heavy-weight meshes contain high concentrations of foreign material and cause excessive inflammatory response. Light-weight meshes have larger pores and they encourage collagen production with integration of the mesh into the abdominal wall with adequate inflammatory response [7].

\section{Materials and methods}

The prospective study was performed from April 2018 to February 2019.

Approval of Ethics Committee in Faculty of Medicine; Benha University was taken before conduction of the study.

Informed consent was obtained from all participating patients before their inclusion at the outpatient clinic and another consent before undergoing operations.

\subsection{Patients}

This study was carried out on 120 patients which was selected from the general surgery outpatient clinic of Benha University Hospital .

\section{Inclusion criteria}

Patients complaining of primary ventral hernia $4 \mathrm{~cm}$ or larger defined by their clinical history, physical examination and radiographic findings.

\section{Exclusion criteria}

1-Complicated cases either obstructed or strangulated.

2-Patients with chest, abdominal diseases or pregnant females.

3-Recurrent or incisional hernia.

\section{Study design}

The number of patients was divided randomly in to two groups:

GroupA:Representing mesh repair using heavyweight mesh ( Prolene mesh).

GroupB:Representing mesh repair using lightweight mesh ( Ultrapro mesh ).

The 2 groups of patients were treated identically in all aspects.

During their intraoperative and postoperative follow up, the predefined outcome measures were recorded and the findings were compared between the two groups 


\section{Study procedure}

All the patients were subjected to the followings:

A-Pre-operative Assessment:

All the patients underwent routine preoperative laboratory studies (complete blood count, blood chemistries), chest radiography, abdominal US and electrocardiogram (if older than 40 years).

\section{B- Operative Technique}

All the patients underwent primary hernia repair using onlay mesh implantation technique divided randomely into two groups:

1- transverse or elliptical skin incision .

2- Dissection of the hernial sac with broad preparation of the fascial edge.

3- Opening of the hernial sac.

4- Inspection of the abdomen to identify adhesions and additional fascial gaps.

5- Detachment of adherent gut tissue

6- Closure of the hernia gap by fascia adaptation with continuous polypropylene suture (prolene no.1, Ethicon) with stitch (tissue bite) intervals of approximately $1 \mathrm{~cm}$.

7- Onlay implantations of the prepared mesh ( Peolene in Group A, Ultrapro in Group B). The distance from suture line is $5 \mathrm{~cm}$ in all directions. The implant is fixed to the aponeurosis without tension, with interrupted non- absorbable suture (prolene 2-0). The technique of fixation is a circular suture after fixing the four edges of the implant.
1- Use of one or two suction drains, careful subcutaneous closure, and skin.

2- closure using skin stapler or prolene $2 / 0$.

\section{C- Outcome measures}

Postoperative (PO) data included, PO hospital stay, time of refeeding, the amount of drain output at first day PO, Permanence of drain, return to normal activities, Duration of analgesics used postoperatively and complications (seroma and wound infection)

Follow-up assessment during the first three postoperative months recorded for post-operative Foreign Body sensation, Pain intensity (PI) measured by Numerical rating scale (NRS) and Quality of life (QOL) assessment using Visual Analogue scale (VAS).

Postoperative (PO) follow-up extending for 18 months for the frequency of recurrence.

\section{Results}

This study included a total of 120 patients with ventral hernia presented for us in outpatient clinic and fulfilling the inclusion criteria in the absence of any of the exclusion criteria. All patients underwent ventral hernia repair half of them by using heavyweight mesh and the other by using lightweight mesh.

\section{a. According to age, gender, weight and BMI}

The age in our study ranged from 21 till 55 with mean value $41.32 \pm 5.37$ at group A and $39.94 \pm 7.22$ at group B Table (1).

Table (1) Demographic data.

\begin{tabular}{lccccc}
\hline & $\begin{array}{c}\text { HW (Prolene) } \\
(\mathbf{n = 6 0})\end{array}$ & $\begin{array}{c}\text { LW (Ultrapro) } \\
(\mathbf{n = 6 0 )}\end{array}$ & Test of Sig. & P & Sig. \\
\hline Gender & $26(43.3 \%)$ & $24(40.0 \%)$ & & & \\
Male & $34(56.7 \%)$ & $36(60.0 \%)$ & 0.137 & 0.793 & NS \\
$\begin{array}{l}\text { Female } \\
\text { Age (years) }\end{array}$ & $25.0-55.0$ & $21.0-52.0$ & & & \\
Min.-Max. & $41.32 \pm 5.37$ & $39.94 \pm 7.22$ & 1.188 & 0.237 & NS \\
Mean \pm SD. &
\end{tabular}

Intraoperative measuring of hernia defects with mean $(9.3 \pm 1.8 \mathrm{~cm}$ of group A and $8.65 \pm 2.61 \mathrm{~cm}$ of group B). There was a non-significant $(\mathrm{p}>0.05)$ difference between both groups as regards the site of hernia and the average size of hernia defects in both groups.

Table (2) Comparison between the two groups according to Site of hernia and size of hernia.

\begin{tabular}{|c|c|c|c|c|c|c|}
\hline & \multicolumn{2}{|c|}{ HW (Prolene) } & \multicolumn{2}{|c|}{ LW(Ultrapro) } & \multirow{2}{*}{ Test of sig. } & \multirow{2}{*}{$\mathbf{P}$} \\
\hline & No. & $\%$ & No. & $\%$ & & \\
\hline Site of hernia & \multicolumn{2}{|c|}{$(n=60)$} & \multicolumn{2}{|c|}{$(n=60)$} & & \\
\hline Epigastric & 8 & $13.3 \%$ & 8 & $13.3 \%$ & & \\
\hline Para umbilical hernia & 36 & $60.0 \%$ & 32 & $53.3 \%$ & $\chi^{2}=$ & ${ }^{\mathrm{MC}} \mathrm{p}=$ \\
\hline Spigelian hernia & 2 & $3.3 \%$ & 1 & $1.6 \%$ & 3.989 & 0.263 \\
\hline Umbilical hernia & 14 & $23.3 \%$ & 19 & $31.6 \%$ & & \\
\hline Size of hernia $(\mathrm{cm})$ & \multicolumn{2}{|c|}{$(n=60)$} & \multicolumn{2}{|c|}{$(n=60)$} & & \\
\hline Min. - Max. & \multirow{2}{*}{\multicolumn{2}{|c|}{$5.0-12.0$}} & & $\mathrm{t}=$ & \\
\hline Mean \pm SD. & & & \multicolumn{2}{|c|}{$8.65 \pm 2.61$} & 1.588 & 0.115 \\
\hline
\end{tabular}

The duration of surgery was shorter in LW group

(group B, mean $56.55 \pm 22.02$ min) than HW group (group 
A, mean65.00 $\pm 25.0 \mathrm{~min}$ ) but with no significant differences between two groups $\mathrm{p}$-value $>0.05$

Table (3) Comparison between the two studied groups according Operation time .

\begin{tabular}{lcccc}
\hline Operation time (min) & $\begin{array}{c}\text { HW (Prolene) }(\mathbf{n}= \\
\mathbf{6 0})\end{array}$ & $\begin{array}{c}\text { LW(Ultrapro) } \\
(\mathbf{n}=\mathbf{6 0})\end{array}$ & $\mathbf{T}$ & $\mathbf{p}$ \\
\hline Min. - Max. & $40-90$ & $30-60$ & -1.965 & 0.052 \\
Mean \pm SD. & $65.00 \pm 25.0$ & $56.55 \pm 22.02$ & \\
\hline
\end{tabular}

All cases showed smooth postoperative recovery and all were discharged after mean $(2.17 \pm 0.88$ days with group A and $1.9 \pm 0.89$ days with group B) with no significant difference between the two groups. All patients discharged with suction drain related to the surgery, the drain output in the first day was more in group A (mean $238.3 \pm 97.98 \mathrm{ml}$ ) than group B (mean 157.3 $\pm 93.36 \mathrm{ml}$ ) with significant value $\mathrm{P}$-value $<0.05$. Drains persisted for (9-18) days of group A that was more than group B at which drains persisted (8-17) days with significant difference between the two groups p-value $<0.05$.
Early mobilization of the patients and refeeding postoperative played an important role in improvement and fast discharge from hospital. all patients started feeding post-operative within (1-2) days of group A and within (13) days of group B. there is no significant difference between the two groups.

All patients return to their normal daily activities within (7-16) days of group B that was faster than group A (9-20) days with significant value $<0.05$.

Table (4) Comparison between the two studied groups according to different parameters.

\begin{tabular}{|c|c|c|c|c|}
\hline & $\begin{array}{c}\text { HW (Prolene) } \\
(\mathbf{n}=60)\end{array}$ & $\begin{array}{c}\text { LW (Ultrapro) } \\
(\mathrm{n}=60)\end{array}$ & $\begin{array}{c}\text { Test of } \\
\text { sig. }\end{array}$ & $\mathbf{P}$ \\
\hline \multicolumn{5}{|l|}{ Post operative hospital stay (days) } \\
\hline Min. - Max. & $1.0-3.0$ & $1.0-4.0$ & \multirow{2}{*}{1.671} & \multirow{2}{*}{0.097} \\
\hline Mean \pm SD. & $2.17 \pm 0.88$ & $1.9 \pm 0.89$ & & \\
\hline \multicolumn{5}{|l|}{ Drain output in first day $(\mathrm{ml})$} \\
\hline Min. - Max. & $50.0-400.0$ & $20.0-400.0$ & \multirow{2}{*}{4.636} & \multirow{2}{*}{$<0.001$} \\
\hline Mean \pm SD. & $238.3 \pm 97.98$ & $157.3 \pm 93.36$ & & \\
\hline \multicolumn{5}{|l|}{ Time of refeeding (days) } \\
\hline Min. - Max. & $1.0-2.0$ & $1.0-3.0$ & \multirow{2}{*}{1.812} & \multirow{2}{*}{0.073} \\
\hline Mean \pm SD. & $1.60 \pm 0.68$ & $1.37 \pm 0.71$ & & \\
\hline \multicolumn{5}{|l|}{ Permanence of drain (days) } \\
\hline Min. - Max. & $9.0-18.0$ & $8.0-17.0$ & \multirow{2}{*}{3.740} & \multirow{2}{*}{$<0.001$} \\
\hline Mean \pm SD. & $14.97 \pm 3.53$ & $12.60 \pm 3.41$ & & \\
\hline \multicolumn{5}{|l|}{ Return to normal activities (days) } \\
\hline Min. - Max. & $9-20$ & $7-16$ & \multirow{2}{*}{3.948} & \multirow{2}{*}{$<0.001$} \\
\hline Mean \pm SD. & $13.5 \pm 3.16$ & $11.3 \pm 2.94$ & & \\
\hline
\end{tabular}

Table (5) Comparison according to early complications ( within 30 days ).

Sixteen cases of seroma were found in both groups; 10 cases in group A and 6 cases in group B. Seroma was treated by drainage through aspiration or removal of one or more stitches. Group A cases showed more amount of seroma persisted for longer periods. Three cases of seroma in group A was complicated by secondary infection. As regard wound infection; group B had 6 cases. Both cases were superficial infection which resolved after good drainage and appropriate antibiotics. group A involved 10 cases of wound infection including the complicated cases of seroma. 6 cases were mild infection in the form of skin erythema and wound edema. The other 2 cases showed purulent discharge. Both cases of aggressive wound infection were diabetics and one of them was markedly obese. There is no reported cases of deep infection reaching the mesh or necessitates mesh removal

Table (6) Comparison according to late complication ( recurrence ).

\begin{tabular}{lcccccc}
\hline & \multicolumn{2}{c}{$\begin{array}{c}\text { HW (Prolene) } \\
(\mathbf{n = 6 0 )}\end{array}$} & \multicolumn{2}{c}{$\begin{array}{c}\text { LW(Ultrapro) } \\
(\mathbf{n = 6 0 )}\end{array}$} & \multirow{2}{*}{$\chi^{\mathbf{2}}$} & \multirow{2}{*}{ FE $_{\mathbf{p}}$} \\
\cline { 2 - 5 } & $\mathbf{N o}$ & $\mathbf{\%}$ & $\mathbf{N o .}$ & $\boldsymbol{\%}$ & & \\
\hline Seroma & 10 & $16.7 \%$ & 6 & $10.0 \%$ & 1.154 & 0.283 \\
Infection & 10 & $16.7 \%$ & 6 & $10.0 \%$ & 1.154 & 0.283 \\
\hline
\end{tabular}

After the end of the follow-up period, there were $6 \quad$ cases of group B ). Most of the cases reported after ( $12-$ reported cases of recurrence ( 4 cases of group A and 2

18) months. All this cases with co-morbidity of heavy 
smoker, chronic cough and DM

Table (7) Comparison between the two studied groups according to post-operative Foreign Body sensation at the 3rd postoperative month.

\begin{tabular}{|c|c|c|c|c|c|c|}
\hline & \multicolumn{2}{|c|}{$\begin{array}{c}\text { HW (Prolene) }(\mathrm{n}= \\
60)\end{array}$} & \multicolumn{2}{|c|}{$\begin{array}{c}\text { LW(Ultrapro) } \\
(n=60)\end{array}$} & \multirow[t]{2}{*}{$\chi^{2}$} & \multirow[t]{2}{*}{${ }^{\mathrm{FE}} \mathbf{p}$} \\
\hline & No. & $\%$ & No. & $\%$ & & \\
\hline Within 6 months & 0 & 0 & 0 & & & \\
\hline 6-12 months & 1 & $1.7 \%$ & 0 & & & \\
\hline 12-18 months & 3 & $5 \%$ & 2 & $3.3 \%$ & & \\
\hline total & 4 & $6.7 \%$ & 2 & $3.3 \%$ & 0.702 & 0.402 \\
\hline
\end{tabular}

Fourteen cases had foreign body sensation (10 cases of group A and 4 cases of group B ), The percentage of patients with foreign body sensation was higher in the HW group (16.7\%) than that of the LW group (6.7\%). The difference between the two groups wasn't statistically significant $(\mathrm{p}=0.088)$.

Table (8) LW and HW groups NRS values.

\begin{tabular}{lcccc}
\hline $\begin{array}{l}\text { Foreign Body } \\
\text { sensation }\end{array}$ & $\begin{array}{c}\text { HW (Prolene) }(\mathbf{n}= \\
\mathbf{6 0})\end{array}$ & $\begin{array}{c}\text { LW(Ultrapro) } \\
(\mathbf{n = 6 0 )}\end{array}$ & $\begin{array}{c}\text { Chi-square } \\
\text { test }\end{array}$ & p-value \\
\hline Positive & $10(16.7 \%)$ & $4(6.7 \%)$ & 2.911 & 0.088 \\
Negative & $50(83.3 \%)$ & $56(53.3 \%)$ & & \multirow{2}{*}{0.080} \\
\hline
\end{tabular}

Pain intensity (PI) measured by Numerical rating scale (NRS);

Preoperative NRS: LW group: 7 patients had a score of (1) and 13 patients had a score of (2). The mean was 1.65. HW group: 9 patients had a score of (1) and 11 patients had a score of (2). The mean was 1.55.

The mean of the NRS values on the 7th POD was higher in the HW group (3.55) than that of the LW group
(3.40). The difference between the two groups was not statistically significant $(\mathrm{p}=0.0 .106)$

The mean of the NRS values on the 3rd postoperative month was higher in the HW group (1.3) than that of the LW group (0.45). The difference between the two groups was not statistically significant $(\mathrm{p}=0.001)$.

Table (9) QOL assessment using VAS for lightweight and HW groups preoperatively and in the 3rd postoperative month.

\begin{tabular}{|c|c|c|c|c|c|}
\hline & & LW group & HW group & Test value & P-value ${ }^{3}$ \\
\hline Preoperative & $\begin{array}{l}\text { Range } \\
\text { Mean } \pm \text { SD }\end{array}$ & $\begin{array}{l}1-2 \\
1.650 \pm 0.489\end{array}$ & $\begin{array}{l}1-2 \\
1.55 \pm 0.510\end{array}$ & 1.096 & 0.275 \\
\hline $7^{\text {th }}$ POD & $\begin{array}{l}\text { Range } \\
\text { Mean } \pm S D\end{array}$ & $\begin{array}{l}3-4 \\
3.40 \pm 0.50\end{array}$ & $\begin{array}{l}3-4 \\
3.55 \pm 0.510\end{array}$ & 1.627 & 0.106 \\
\hline$P$-value ${ }^{1}$ & & $0.000 *$ & $0.000 *$ & & \\
\hline $\begin{array}{l}3^{\text {rd }} \text { postoperative month } \\
\text { P-value }\end{array}$ & $\begin{array}{l}\text { Range } \\
\text { Mean } \pm \text { SD }\end{array}$ & $\begin{array}{l}0-4 \\
0.45 \pm 1.14 \\
0.000 *\end{array}$ & $\begin{array}{l}0-5 \\
1.30 \pm 0.186 \\
0.293\end{array}$ & 5.700 & $0.001 *$ \\
\hline
\end{tabular}

Quality of life (QOL) assessment using Visual Analogue scale (VAS).

The mean of the preoperative VAS values was higher in the LW groups (63.5) than that of the HW group (58.3). The difference between the two groups was not statistically significant $(\mathrm{p}=0.275)$.

\begin{tabular}{lll} 
& & \\
\hline \multirow{2}{*}{ Preoperative } & Range & LW group \\
& Mean \pm SD & $63.6-85.2$ \\
$\mathbf{3}^{\text {rd }}$ POM & Range & $59-95.8$ \\
P-value $^{1}$ & Mean $\pm S D$ & $88.15 \pm 8.20$ \\
& & $0.001^{*}$ \\
\hline
\end{tabular}

The mean of the VAS values in the 3rd postoperative month was higher in the LW groups (88.15) than that of the HW group (65.21). The difference between the two groups was not statistically significant $(\mathrm{p}=0.106)$.

\begin{tabular}{|c|c|c|}
\hline HW group & Test value & P-value ${ }^{2}$ \\
\hline $\begin{array}{l}49.8-88.9 \\
58.3 \pm 8.47\end{array}$ & 1.096 & 0.275 \\
\hline $\begin{array}{l}55.6-95.8 \\
65.2 \pm 8.41 \\
0.001 *\end{array}$ & 1.627 & 0.106 \\
\hline
\end{tabular}

In the present study 120 patients with primary ventral hernias were included. Half of these patients were

\section{Discussion}


operated using Heavy-weight mesh and the other group with Light-weight mesh.

There was no significance between the two groups regarding gender, age and BMI. The study underwent on 50 males and 70 females. Minimum age was 21 years and maximum age was 55 years. BMI with no significant differences between two groups p-value $>0.05$.

In this study, Regarding types of hernia, The commonest type was para umbilical hernia, umbilical hernia then epigastric hernia then spigelian hernia, types and size of hernia were insignificant between two groups .

In agreement with our result Hussain et al found that most common type of primary ventral hernia was para umbilical hernia (42\%), Umbilical (39.34\%), Spigelian hernia and Epigastric hernia $(6.55 \%)$ [8].

In the present study we found that permanence of drain was around 2 weeks in HW group and around 10 days in LW group p-value $<0.001$

Zhang et al not agree with this study as they found that the rates of wound drainage were significantly lower with HW group than in LW group in study of laparoscopic ventral hernia repair using a bridging technique [9].Fabozzi et al agree with our result as they found that permanence of the drain was longer on HW repair group than LW repair group as there is less tissue reaction with LW meshes [10].

In this study, the percentage of patient with seroma was higher in the HW group (16.7\%) than that of the LW group $(10 \%)$. The difference between the two groups was statistically insignificant $(\mathrm{p}=0.283)$. Our results are consistent with the results of the meta-analysis reported by Uzzaman et al in which 6 randomized controlled trials assessed the development of postoperative seroma. There was no significant difference in the use of LW or HW mesh on seroma formation $(\mathrm{p}=0.15)$. Our results are also consistent with what is reported by Zhong et al in which seroma was reported in 2 studies. The analysis comparing LW and $\mathrm{HW}$ meshes was not significantly different $(\mathrm{OR}=$ $0.89 ; 95 \%$ CI - 0.44-1.79) [11,12].

In this study, the return to normal activities values of our patients were assessed. They were faster in the LW group (10.00) days than that of the HW group (14.00) days showing statistically significant difference $(\mathrm{p}=0.001)$.

In Modiya et al study in LW meshes surgery 23 (92\%) patient returned to their work within 6th to 10th postoperative day. In HW meshes surgery 20 (80\%) patient returned to their work within 10 th to 12 th post-operative day [13].

Malik et al found that the overall incidence of complications was significantly higher in Group B with HW mesh repair compared to Group A with LW mesh repair in the form of (Prolonged Ileus, Haematoma, Intestinal injury, Seroma, Bleeding during adhesiolysis, Cellulitis of wound site). The recurrence rate in both groups was statistically significant $(\mathrm{p}<0.05)$. Recurrences were mainly seen in patients who developed overwhelming post-operative wound infection. Most of the recurrences occurred in patients who were operated early in the series and more so with huge hernias [14].

The other primary outcome measure was the foreign body sensation which was found to be less frequent in the LW group than that of the HW group when it was assessed at the 3 rd postoperative month. The percentage of

our patients with foreign body sensation was higher in the HW group (16.7\%) than that of the LW group (6.4\%). The difference between the two groups was statistically not significant $(\mathrm{p}=0.088)$. Our results are not consistent with the results of the meta-analysis reported by Uzzaman et al. (2012) in which 2 randomized controlled trials assessed the feeling of foreign body sensation at 6 months after ventral repair. There were 76 patients (26.1\%) reporting foreign body sensation in the HW group compared to 47 patients $(15.2 \%)$ in the LW group. The difference between the two groups was statistically significant $(\mathrm{p}=0.001)$. Also the meta-analysis done by Zhong et al. (2013) including 4 studies, reported significantly lower sensation of a foreign body with a LW mesh [11].

In this study, the pain intensity (PI) values of on 7th POD showed no significant difference between the LW group and the HW group. The mean of the NRS values was higher in the HW group (3.55) than that of the LW group (3.40).

In the current study, the number of patients complaining of pain in the 3rd postoperative month was significantly lower in the LW group (3 patients representing $15 \%$ ) than that of the $\mathrm{HW}$ group (7 patients representing $35 \%$ ), the difference between the two groups was statistically significant $(\mathrm{p}=0.001)$.

According to hernia recurrence in both groups during the period of follow-up (6 - $12-18$ months) in our patients, 4 patients reported with $\mathrm{HW}$ mesh repair and 2 patients with LW mesh repair.

The two major meta-analysis Uzzaman et al. (2012) and Zhong et al. (2013) have shown recurrence rates for the LW and HW groups to be (2,9\%) and (2.2\%) respectively with no significant difference

In agreement with this study Zhang et al found that there was no significant difference between the two groups in the incidences of hernia recurrence and other postoperative complications, as well as in postoperative pain [9].

In this study, the QOL values of our patients were assessed by VAS in the 3rd postoperative month. They were higher in the LW group (88.15) than that of the HW group (65.21) showing statistically insignificant difference $(p=0.106)$.In this work, QOL values of the both groups in the 3rd postoperative month were significantly higher when compared to the baseline (preoperative values). In the LW group; the mean of the postoperative VAS values (88.15) was higher than the mean of the preoperative VAS values (63.5). The difference between the two groups was statistically significant $(\mathrm{p}=0.001)$. While, in the HW group; the mean of the postoperative VAS values (65.2) was higher than the mean of the preoperative VAS values (58.3). The difference between the two groups was statistically significant $(\mathrm{p}=0.001)$.

\section{Conclusion}

The LW mesh offers benefits over HW mesh for 
ventral hernia repair by reducing the incidence of chronic pain and foreign body sensation. Complications - seroma and infection - with LW meshes were less than HW meshes, recurrence rate was high with HW meshes than LW meshes .

It could be concluded that the repair of primary ventral hernia cases can be made with light weight mesh or heavy weight mesh, but the cost-benefits of using LW mesh is still main obstacles. We suggest that light weight mesh is an option for repair of primary ventral hernia as its complications are less and the quality of life is better.

\section{References}

[1] D.Earle, J. S.Roth, A.Saber, S.Haggerty, J. F.Bradley, R.Fanelli, , SAGES Guidelines Committee. SAGES guidelines for laparoscopic ventral hernia repair. Surgical endoscopy, Vol.30(8), PP.3163-3183,2016.

[2] F. Muysoms, M. Miserez, F. Berrevoet, G.Campanelli, G. Champault , Classification of primary and incisional abdominal wall hernias. Hernia, Vol.13, PP.07-414,2009.

[3] J. S. Ashley, Maingot's abdominal operations. McGraw-Hill Publishing, 2007.

[4] S. Bringman, J. Conze, D. Cuccurullo, J. Deprest, Hernia repair: the search for ideal meshes. Hernia, Vol.14(1), PP.81-7, 2010.

[5] W.S. Cobb, J.M. Burns, R.D. Peindl, A.M. Carbonell, B.D. Matthews, extile analysis of heavy-weight, mid weight and light-weight polypropylene mesh in a porcine ventralhernia model. J Surg Res, Vol.136, pp.1-7, 2006.

[6] U. Klinge, J. Conze, C.J. Krones, V.Schumpelick ,Incisional hernia: open techniques. World Journal of Surgery, Vol.29 (8), PP.1066-72,2005.
[7] E.K. Aasvang, E. Gmaehle, J.B. Hansen, B. Gmaehle, J.L. Forman, Predictive risk factors for persistent postherniotomy pain. Anesthesiology , PP.112957969,2010 .

[8] A.Hussain, H. Mahmood, J .Nicholls, Laparoscopic ventral hernia repair. Our experience of 61 consecutive series: Prospective study International Journal of Surgery, Vol.6, PP.15-19, 2008.

[9] Y. Zhang, H. Zhou, Y. Chai, Laparoscopic Versus Open Incisional and Ventral Hernia Repair: A Systematic Review and Meta-analysis.World J Surg , Vol.38, PP.2233-2240,2014.

[10]M. Fabozzi, R. Allieta, L .Grimaldi, Open vs laparoscopic repair of abdominal hernia: a case control study in over 60 years old patients. BMC Surgery, Vol.13(Suppl 1), pp.A19, 2013.

[11]M. M.Uzzaman, K.Ratnasingham, N.Ashraf, Metaanalysis of randomized controlled trials comparing lightweight and heavyweight mesh for Lichtenstein inguinal hernia repair. Hernia, Vol.16(5), PP.505$518,2012$.

[12]C.Zhong, B.Wu, Z.Yang, X.Deng, A meta-analysis comparing lightweight meshes with heavyweight meshes in Lichtenstein inguinal hernia repair. Surgical innovation, Vol.20(1), PP.24-31,2013.

[13] S.Modiya, D.Moszkowicz, T.Poghosyan, A.Beauchet, Comparison of complete versus partial mesh removal for the treatment of chronic mesh infection after abdominal wall hernia repair. Hernia, Vol.22(5), PP.773-779, 2018.

[14] A.M.Malik. Laparoscopic versus open repair of paraumbilical hernia. Is it a good alternative? JPMA , Vol.65,pp, 865,2015. 